\title{
Artikel
}

\section{Participatie bij besluitvorming over aanleg, verlegging of versterking van primaire waterkeringen}

\author{
Mr. H.A.J. (Henk) Gierveld*
}

\section{Inleiding}

Op 5 oktober 2017 vond onder leiding van prof. mr. Peter van Buuren een studiemiddag plaats over projectbesluitvorming voor waterbeheerders. Aan de hand van de casus 'De meanderende Maas' werd stilgestaan bij de besluitvorming op grond van de Waterwet (Wtw) en de Wet ruimtelijke ordening (Wro), maar ook vooruitgekeken naar de besluitvorming op grond van de Omgevingswet.

Frank Groothuijse ging in op de reikwijdte en inhoud van het projectbesluit, Hans Besselink op de integrale besluitvorming. Hun artikelen, bewerkingen van de door hen gehouden presentaties, treft $\mathrm{u}$ eveneens aan in dit nummer. ${ }^{1}$

In de uitwerking van mijn bijdrage - codificering van het participatiebeginsel - wil ik beginnen met enkele algemene opmerkingen over de projectprocedure op grond van de Omgevingswet (hierna ook: Ow), om vervolgens dieper in te gaan op de zogenoemde voorne-

Mr. H.A.J. Gierveld was ten tijde van het schrijven van deze bijdrage wetgevingsjurist bij de Hoofddirectie Bestuurlijke en Juridische Zaken van het ministerie van Infrastructuur en Milieu. Hij is lid van de redactie van het Tijdschrift voor Omgevingsrecht en tevens verbonden als geassocieerd medewerker aan het Utrecht Centre for Water, Oceans and Sustainability Law van de Universiteit Utrecht.

1. Meer informatie over de casus, de presentaties en het verslag van de bijeenkomst is te vinden op www.uu.nl/utrecht-centre-for-water-oceans -and-sustainability-law. menprocedure en het overgangsrecht zoals dat is opgenomen in de Invoeringswet Omgevingswet.

Bij de bespreking van wetteksten ga ik uit van de tekst van de Omgevingswet, zoals die verschenen is in het Staatsblad. ${ }^{2}$ Bij het vermelden van artikelen uit de Invoeringswet Omgevingswet en het Omgevingsbesluit (hierna ook: $\mathrm{Ob}$ ) ga ik uit van de concept-versies van 30 juni 2017. ${ }^{3}$ In eerdere publicaties ben ik uitgebreid ingegaan op de projectprocedure onder de Omgevingswet. ${ }^{4}$ In die publicaties lag het accent op de Tracéwet (hierna ook: Tw). In dit artikel zal ik op enkele plaatsen daarnaar verwijzen voor meer achtergrondinformatie, omdat de Ow-besluitvorming over aanleg, verlegging en versterking van primaire waterkeringen gemodelleerd is naar de $\mathrm{Tw}$-procedure voor de aanleg en wijziging van hoofdwegen, landelijke spoorwegen en hoofdvaarwegen.

\section{De projectprocedure}

Een procedure voor de realisatie van een project kent drie fasen. De fase voorafgaande aan de daadwerkelijke besluitvorming, die van die besluitvorming en de fase van de projectuitvoering.

In de Tracéwet zijn de drie fasen ondergebracht in drie aparte hoofdstukken, te weten hoofdstuk II (startbeslis-

Stb. 2016, 156

Te vinden op www.omgevingswetportaal.nl.

H.A.J. Gierveld, Besluitvorming over de aanleg en wijziging van hoofdinfrastructuur, Den Haag: Instituut voor Bouwrecht 2017 en H.A.J. Gierveld, De juridificering van de voornemenprocedure onder de Omgevingswet, TBR 2016, afl. 4, p. 307-324. 
sing en verkenning), III (tracébesluit) en IV (projectuitvoering). In het hoofdstuk over de projectuitvoering zijn bepalingen opgenomen over het coördineren van de uitvoeringsbesluiten.

De Wro en de Wtw kennen geen wettelijke regeling van de aan de daadwerkelijke besluitvorming voorafgaande verkenningsfase. Beide wetten kennen wel bepalingen over inpassingsplannen respectievelijk projectplannen en over het verkriigen van de benodigde uitvoeringsbesluiten.

Het Ow-projectbesluit vervangt het inpassingsplan, het tracébesluit, het projectplan uit de Wtw en de coördinatieregelingen uit de Wro, de Tracéwet, de Wtw en de Ontgrondingenwet, aldus de memorie van toelichting. ${ }^{5}$

In de Omgevingswet is in afdeling 5.2 een aparte paragraaf gewijd aan de verkenningsfase (par. 5.2.2) en het projectbesluit (par. 5.2.3). Echter, de bepalingen over de coördinatie van uitvoeringsbesluiten staan niet in de Omgevingswet, maar worden ondergebracht in een nieuw in te richten afdeling 3.5 van de Algemene wet bestuursrecht (Awb). ${ }^{6}$

\section{Wettelijke verankering}

Sinds 1 januari 2012 is in de Tracéwet de verkenningsfase wettelijk verankerd en sinds jaar en dag wordt er door Rijkswaterstaat en ProRail volop geparticipeerd. Tot 1 januari 2012 niet vanwege een wettelijke verplichting, die was er immers niet, maar omdat het nuttig werd gevonden de omgeving vroeg te betrekken en gebruik te maken van de denkkracht, creativiteit en kennis van mensen die werken of wonen in de omgeving. Het te nemen besluit kan er alleen maar beter van worden. De omgeving wordt in een vroeg stadium betrokken, maar participatie kan zich ook uitstrekken tot de uitvoeringsfase en ingezet worden om te komen tot goede oplossingen en afspraken om bouwhinder zo veel mogelijk te beperken. Zoals gezegd: tot 1 januari 2012 ontbrak een wettelijke regeling, wel verschenen er rapporten en codes waarin de best practices waren opgenomen. ${ }^{7}$ De praktijk kon daar goed mee uit de voeten, aan een wettelijke regeling was dan ook geen behoefte.

Dat de verkenningsfase ook in de Tracéwet zou worden opgenomen, is te danken aan het rapport 'Sneller en Beter' van de Commissie besluitvorming infrastructurele projecten (beter bekend als de commissie-Elverding). Ik beschouw het benadrukken van het vroegtijdig

5. Kamerstukken II 2013/14, 33 962, nr. 3, p. 54.

6. Mij is niet duidelijk waarom niet in par. 5.2.4 (onder vernummering van de al bestaande par. 5.2.4 naar 5.2.5) de coördinatieregeling van onder meer Waterwet, Wro en Tracéwet is opgenomen. Het zou de kenbaarheid van de projectprocedure zeer ten goede komen. Verdere behandeling van de juiste plaats van de uitvoeringsbepalingenmodule blijft in deze bijdrage over de verkenningsfase echter buiten beschouwing.

7. Thans vigerend is de Code Maatschappelijke Participatie, opgesteld door het ministerie, te vinden op www.platformparticipatie.nl. betrekken van de omgeving als de belangrijkste anbeveling van de commissie. Over de vraag of die participatie ook wettelijk verankerd zou moeten worden, was eigenlijk geen discussie meer $^{8}$ mogelijk: de regering wilde dat. ${ }^{9}$ In een eerdere brief werd het belang van participatie aangevoerd als reden voor een wettelijke regeling:

'Het kabinet wil het belang van participatie tot uitdrukking laten komen door deze wettelijk te verankeren gericht op verantwoording achteraf. In lijn met het advies van de commissie en de ervaringen met Inspraak Nieuwe Stijl wil het kabinet niet de vorm en de te volgen procedure vastleggen. Elk project is uniek en vergt een maatwerkaanpak. Bovendien zou het vastleggen van voorschriften over de wijze waarop participatie dient plaats te vinden leiden tot juridificering, die het kabinet juist wil tegengaan. Door de participatieplicht vormvrij in te vullen, kan wel marginaal worden getoetst of participatie heeft plaatsgevonden. ${ }^{10}$

Op zich zijn er ook voordelen verbonden aan een wettelijke regeling. De wet krijgt dan het karakter van een draaiboek, zodat iedereen kan nalezen hoe de te doorlopen procedure eruitziet. Bezwaren zijn er als de regeling niet duidelijk is en inspiratie wordt voor bezwaarmakers om aan te geven dat het besluit vernietigd moet worden, omdat er onvoldoende is geparticipeerd. ${ }^{11}$

\section{Participatieregels in Tracéwet, Omgevingswet en Omgevingsbesluit}

Hoofdstuk 2 van de Tracéwet kent zes artikelen over de verkenningsfase: art. 2 over de startbeslissing, art. 3 over de verkenning en art. $4 \mathrm{t} / \mathrm{m} 7$ over de structuurvisie en de daarin opgenomen voorkeursbeslissing. De Tracéwet kent geen AMvB.

Paragraaf 5.2.2 van de Omgevingswet bevat drie artikelen over de verkenningsfase: art. 5.47 over het voornemen, art. 5.48 over de verkenning en art. 5.49 over de voorkeursbeslissing. Het vierde artikel in die paragraaf, art. 5.50, gaat over de (niet-)toepasselijkheid van paragraaf 5.2.2 en wordt verder niet besproken. ${ }^{12}$

In afdeling 4.1 van het Omgevingsbesluit zijn vier artikelen gewijd aan de voornemenfase: art. 4.1 gaat over de inhoud van het voornemen, art. 4.2 over de vraag wie betrokken worden in het kader van de participatie, art. 4.3 over de verplichte voorkeursbeslissing en art. 4.4 over de inhoud van de voorkeursbeslissing. Aanvullende

8. Voor een wetgevingsjurist is dat een belangrijke vraag.

9. Kamerstukken II 2007/08, 29385 , nr. 45, p. 7-9.

10. Kamerstukken II 2007/08, 29 385, nr. 19.

11. Zie bijv. ABRvS 5 augustus 2015, ECLI:NL:RVS:2015:2485 (Tracébesluit A59 Drongelens Kanaal).

12. Zie over de overbodigheid van dat artikel Gierveld 2017, p. 236-237. 
bepalingen in het Omgevingsbesluit zijn niet uitgesloten. Er zijn drie grondslagen in de Omgevingswet die aanvulling mogelijk maken: art. 5.47, tweede lid, art. 5.47 , vijfde lid, en art. 16.88, eerste lid, aanhef en onder d.

\section{Verbreding en veralgemenisering}

In de Tracéwet is de verkenningsfase onderdeel gemaakt van de wettelijk voorgeschreven procedure. In de Omgevingswet is die verankering overgenomen en verbreed naar andere projectprocedures dan die betrekking hebben op de aanleg en wijziging van autowegen, landelijke spoorwegen en hoofdvaarwegen. Het projectbesluit vervangt immers het inpassingsplan, het tracébesluit, het projectplan en de coördinatieregelingen uit de Wro, de Tracéwet, de Wtw en de Ontgrondingenwet. ${ }^{13}$

Het samenbrengen van verschillende besluiten in een nieuw besluit, dat zowel geschikt moet zijn voor bijvoorbeeld de aanleg van wegen, de versterking van primaire waterkeringen en het beschermen van gebieden als voor het tegengaan van projecten of het wegbestemmen van overtollige kantoorcapaciteit, zorgt voor meer algemeen geredigeerde artikelen en nieuwe begrippen. Ook de verkenningsfase van de projectprocedure - thans nog alleen in de Tracéwet - is veralgemeniseerd om omgevingsrechtbrede toepassing mogelijk te maken. De Owprojectprocedure is gemodelleerd naar de $\mathrm{Tw}$-procedure en het is ook niet zo moeilijk om in de genoemde artikelen het Tw-model terug te vinden. Wat wel opvalt, is dat door de verbrede toepassing van de projectprocedure de bepalingen een hoog abstractieniveau hebben gekregen. Dat is enerzijds het gevolg van het zich moeten ontdoen van sectoraal specifieke kenmerken, maar anderzijds ook het automatische gevolg van de veralgemenisering.

Deze vertaalslag is begrijpelijk en ook wel terecht. Wel moet worden voorkomen dat de regels onduidelijk worden en in de praktijk moeilijk of niet uitvoerbaar worden. Dat is naar mijn mening wel gebeurd en vooral als gevolg van de aangenomen amendementen. ${ }^{14} \mathrm{Ik}$ zal dat illustreren aan de hand van de verkenningsfase, zoals die opgenomen is in de Tracéwet en in de Omgevingswet.

13. Mij is niet duidelijk welke projectbesluitbepalingen kunnen worden gezien als vervanging van genoemde coördinatieregelingen. Wellicht dat daarmee gedoeld is op de mogelijkheid om vergunningen op te nemen in het projectbesluit (art. 5.52), zodat als alle vergunningen worden opgenomen er niks meer te coördineren valt? Voor de uitleg van art. 5.52 en hoe daarmee om te gaan, verwijs ik naar de bijdrage van Hans Besselink.

14. Het dysfemisme verminking geeft beter aan wat het effect van een amendement kan zijn.

\section{Art. 5.47 Ow (in relatie tot art. 2 Tw)}

Het eerste artikel van paragraaf 5.2.2 is art. 5.47. Hieronder is in cursief aangegeven welke onderdelen via amendering zijn toegevoegd aan het artikel:

\section{'Artikel 5.47 (voornemen)}

1. Het bevoegd gezag geeft kennis van zijn voornemen om een verkenning uit te voeren naar een mogelijk bestaande of toekomstige opgave in de fysieke leefomgeving en om:

a. een projectbesluit vast te stellen zonder daaraan voorafgaande voorkeursbeslissing, of

b. een projectbesluit vast te stellen en ter voorbereiding daarvan een voorkeursbeslissing te nemen.

2. Bij algemene maatregel van bestuur of bij besluit van het bevoegd gezag wordt bepaald wanneer een voorkeursbeslissing in ieder geval wordt genomen.

3. Bij het voornemen stelt het bevoegd gezag met het oog op de verkenning een ieder in de gelegenheid, binnen een door hem te stellen termijn, mogelijke oplossingen voor de opgave voor te dragen. Het bevoegd gezag geeft daarbij uitgangspunten aan voor het redelijkermijs in beschouming nemen van die oplossingen.

4. Uiterlijk bij aanvang van de verkenning geeft het bevoegd gezag, onverminderd het derde lid, kennis van de mijze maarop burgers, bedrijven, maatschappelijke organisaties en bestuursorganen zullen morden betrokken.

5. Bij of krachtens algemene maatregel van bestuur morden nadere regels gesteld over het bepaalde in het vierde lid.'

In art. 2 van de Tracéwet is opgeschreven wat er in een startbeslissing komt te staan. In art. 5.47 van de Omgevingswet wordt slechts aangegeven of er al dan niet een voorkeursbeslissing wordt genomen. Echter, in art. 4.1 van het Omgevingsbesluit heeft de inhoud van het voornemen - vergelijkbaar met het Tw-artikel - wel een plaatsje gekregen. De artikelen (dus inclusief art. 4.1 $\mathrm{Ob}$ ) met betrekking tot de inhoud zijn dan vergelijkbaar.

Het tweede lid van art. 5.47 van de Omgevingswet is wat ongelukkig geformuleerd. Uit precieze lezing van het artikellid volgt dat het dagelijks bestuur van elk waterschap (evenals de andere bevoegde gezagen) aan de bak moet met het schrijven van een besluit, waarin komt te staan in welke gevallen in ieder geval een voorkeursbeslissing wordt genomen. Ik vermoed echter dat het alleen maar de bedoeling was dat het bevoegd gezag in het voornemen kan aangeven of in de verkenningsfase naar de aan de orde zijnde opgave in de fysieke leefomgeving voorzien zal worden in een apart moment - de voorkeursbeslissing - voordat de fase van de daadwerkelijke projectbesluitvorming begint. ${ }^{15}$

15. Uitgebreid over het tweede lid: Gierveld 2017, p. 229-230 
Art. 5.47, derde lid, van de Omgevingswet vraagt het bevoegd gezag om bij het voornemen met het oog op de verkenning eenieder in de gelegenheid te stellen binnen een door hem te stellen termijn mogelijke oplossingen voor de opgave aan te dragen. Ingevolge een amendement van de leden Dik-Faber en Van Veldhoven is het derde lid van een tweede volzin voorzien. ${ }^{16}$

De nieuwe volzin is verwarrend. Het voornemen zou niet meer moeten bevatten dan een beschrijving van die opgave en op welke wijze het bevoegd gezag kennis en inzichten wil verkrijgen. Het is een open verkenningsfase, je moet niet te vroeg met oplossingen willen komen en ook openstaan voor andere zienswijzen dan oplossingen. Aan het begin van de verkenning, waarin de opgave wellicht nog niet helemaal duidelijk is, zijn oplossingen helemaal niet welkom. Ik zie ook niet hoe het bevoegd gezag in deze fase al met heldere uitgangspunten kan komen voor het redelijkerwijs in beschouwing kunnen nemen van aangedragen oplossingen.

Reeds in art. 5.48, eerste lid, onder c, van de Omgevingswet staat dat het bevoegd gezag de nodige kennis en inzichten vergaart over de mogelijke oplossingen voor de opgave. Het derde lid van art. 5.47 kan dan ook beter worden geschrapt. ${ }^{17}$

Met het vierde lid wordt alsnog hetgeen in art. 2, derde lid, onder c, van de Tracéwet staat, overgenomen. Het was echter beter geweest om via een motie de regering te vragen om het gewenste artikel toe te voegen aan (art. 4.1 van) het Omgevingsbesluit als inhoudsvereiste aan het voornemen. Het vijfde lid, een nieuwe grondslag, zouden we dan ook meteen kwijt zijn. ${ }^{18}$ Het nadeel van het vierde lid is dat er naast de kennisgeving van het voornemen ook nog kennis wordt of kan worden gegeven van de aanvang van de verkenning. Uiterlijk op dat moment - het hoeft dus niet reeds bij kennisgeving van het voornemen - moet er een participatieplan zijn. Het doet echter geforceerd aan om de start van de verkenning niet samen te laten vallen met de kennisgeving van het voornemen. Het gevolg is dat er dan naast de kennisgeving van het voornemen ook nog een kennisgeving van de aanvang van de verkenning kan verschijnen, waarvan publicatie in de Staatscourant weer niet is voorgeschreven. ${ }^{19}$

Het lijkt me nuttig als in de praktijk direct bij het voornemen (tevens start van de verkenning) wordt aangegeven hoe er zal worden geparticipeerd.

In paragraaf 5 ben ik ingegaan op de noodzaak om bij verbreding van het toepassingsbereik regelgeving te abstraheren en te ontdoen van sectorale elementen. De Tweede Kamer doet eigenlijk precies het omgekeerde. Immers, in de toelichting van het amendement wordt uitsluitend ingegaan op windenergieprojecten. ${ }^{20}$ Het gevolg is dat regels voor de projectprocedure aan de

16. Kamerstukken II 2014/15, 33 962, nr. 109.

17. Uitgebreid over het derde lid: Gierveld 2017, p. 230-232.

18. Evenals art. $4.2 \mathrm{Ob}$

19. Vgl. art. 4.2, tweede lid, met art. 4.1, tweede lid, Ob.

20. Kamerstukken II 2014/15, 33 962, nr. 163.
Omgevingswet worden toegevoegd, die ontleend zijn aan een voorbeeld van sectorale besluitvorming, maar wel gelden voor alle projectbesluiten. Uit het amendement blijkt niet dat de indieners zich bewust waren van die brede reikwijdte en zich de vraag hebben gesteld of de afspraken over participatieplannen, gemaakt in het Energieakkoord, ook geschikt zijn voor regels ten aanzien van water, wegenaanleg, natuurbescherming, enzovoort. ${ }^{21}$

\section{Art. 5.48 Ow (in relatie tot art. $3 \mathrm{Tw}$ )}

Art. 5.48 van de Omgevingswet, zoals opgenomen in het oorspronkelijk voorstel, kwam overeen met art. 3 van de Tracéwet. Door amendering (cursief weergegeven) heeft het artikel er twee leden bij gekregen: ${ }^{22}$

\section{'Artikel 5.48 (verkenning)}

1. Bij de verkenning vergaart het bevoegd gezag de nodige kennis en inzichten over:

a. de aard van de opgave,

b. de voor de fysieke leefomgeving relevante ontwikkelingen, en

c. de mogelijke oplossingen voor die opgave.

2. Degene die een mogelijke oplossing als bedoeld in artikel 5.47, derde lid, heeft voorgedragen, kan daarbij verzoeken dat het bevoegd gezag daarover advies vraagt aan een onafhankelijke deskundige. Het bevoegd gezag kan ook ambtshalve een onafhankelijke deskundige verzoeken te adviseren.

3. Het bevoegd gezag beslist of de voorgedragen mogelijke oplossingen redelijkermijs in beschouming moeten morden genomen.'

Het nieuwe tweede artikellid lijkt een grondslag te willen bieden voor de andrager van een oplossing om bedoeld verzoek te kunnen doen. Maar dat is niet nodig. Het staat iemand die een oplossing voordraagt toch al vrij om het bevoegd gezag te verzoeken daarover advies te vragen aan een onafhankelijke deskundige, en ook het bevoegd gezag is vrij om uit eigen beweging een onafhankelijke deskundige om advies te vragen. In het laatste geval zal er advies worden uitgebracht, in het eerste geval kan advies achterwege blijven.

Ook het nieuwe derde lid lijkt me niet nuttig. Het gaat niet om de vraag of voorgedragen mogelijke oplossingen redelijkerwijs in beschouwing moeten worden genomen, maar om de vraag of de mogelijke oplossingen redelijkerwijs in beschouwing te nemen alternatieven zijn. Als dat zo is, dan worden ze gewoon meegenomen in het milieueffectrapport.

Dat het derde lid uitgaat van een separaat besluit, blijkt uit de toelichting bij het amendement, waar staat dat tegen een besluit op grond van het derde lid geen

21. Uitgebreid over het vierde en vijfde lid: Gierveld 2017, p. 232-233.

22. Kamerstukken II 2014/15, 33 962, nr. 109. 
bezwaar en beroep open zal staan en dat uitsluiting van bezwaar en beroep nog zal worden geregeld via aanpassing van bijlage 2 van de Awb. Het is echter niet wenselijk om de onderzoeksfase - de verkenningsfase - te voorzien van wettelijke tussenbeslissingen. Het is beter om het derde lid te schrappen en de burger die meent dat zijn aangedragen oplossing niet serieus wordt genomen, te adviseren om, zoals ook thans mogelijk is, een zienswijze in te dienen tegen een ontwerp-projectbesluit/MER of een beroepsgrond naar voren te brengen inhoudende het ten onrechte ontbreken van een uitwerking van een kansrijke oplossing.

\section{Art. 5.49 Ow (in relatie tot art. $5 \mathrm{Tw}$ )}

Het derde artikel van paragraaf 5.2.2 is gewijd aan de voorkeursbeslissing. Verwacht wordt - op basis van de ervaringen met de Tracéwet - dat de meeste verkenningsfasen doorlopen worden zonder dat een expliciete voorkeursbeslissing wordt genomen. In art. 5.49 van de Omgevingswet wordt de 'inhoud' van een dergelijke beslissing gegeven:
'Artikel 5.49 (voorkeursbeslissing)
De voorkeursbeslissing kan inhouden:
a. het uitvoeren van een project,
b. een oplossing zonder project,
c. een combinatie van de onderdelen a of $b$ met de uitvoering van andere projecten, of
d. het niet uitwerken van een oplossing.'

Art. 5 van de Tracéwet, dat model heeft gestaan voor art. 5.49, makt duidelijk dat de verkenning onderdeel uitmaakt van een procedure over de aanleg of wijziging van hoofdwegen, landelijke spoorwegen of hoofdvaarwegen:

'1 De voorkeur, bedoeld in artikel 4, eerste lid, onderdeel c, kan inhouden:

a. de aanleg of wijziging van een hoofdweg, landelijke spoorweg of hoofdvaarweg;

b. een oplossing zonder aanleg of wijziging van een hoofdweg, landelijke spoorweg of hoofdvaarweg;

c. een combinatie van $a$ of $b$ met de realisering van andere ruimtelijke projecten;

d. dat er geen oplossing wordt uitgewerkt.'

Dat artikellid is geschreven op basis van de ervaringen met het zogenaamde positieve of negatieve standpunt op grond van de Tracéwet van vóór 2012. Onderdeel b heeft betrekking op problemen op de weg die beter opgelost konden worden met verbetering van het openbaar vervoer, andere routering, de invoering van beprijzing, betere spreiding van werktijden, enzovoort. De gedachte was dat niet elke file opgelost behoefde te worden met een extra rijstrook. Art. 5 is ook voorzien van een tweede lid, waarin staat dat als besloten wordt om een weg aan te leggen of te verbreden, dat dan ook een eerste indicatie wordt gegeven van de te treffen maatregelen en ingegaan wordt op de financiële uitvoerbaarheid.

Art. $5.49 \mathrm{Ow}$ lijkt op het eerste gezicht op het Tw-artikellid. Omdat de Ow-projectprocedure ook ziet op andere projecten dan de aanleg of wijziging van hoofdinfrastructuur is de bepaling (terecht) ontdaan van verwijzingen naar de hoofdinfrastructuur, maar het resultaat van deze veralgemenisering is dat er een lege, nietszeggende bepaling overblijft. Immers, ook zonder de thans limitatief gemaakte ${ }^{23}$ - opsomming moge duidelijk zijn dat in een voorkeursbeslissing komt te staan of en wat de volgende procedurestap zal zijn. De term voorkeursbeslissing geeft dat al aan.

In het systeem van de Omgevingswet kunnen inhoudsvereisten van een voorkeursbeslissing ook worden opgenomen in het Omgevingsbesluit. Daar is thans alleen voorzien in art. 4.4, waarin staat dat de voorkeursbeslissing in ieder geval vermeldt welke oplossing de voorkeur van het bevoegd gezag heeft, hoe burgers, bedrijven, maatschappelijke organisaties en bestuursorganen zijn betrokken en wat de resultaten zijn van de uitgevoerde verkenning, waarbij in ieder geval wordt ingegaan op de door derden voorgedragen mogelijke oplossingen en de daarover door deskundigen uitgebrachte adviezen. ${ }^{24}$ Het systeem van de Omgevingswet leidt hier wel tot een inhoudsloos art. 5.49.25 Dat kan worden verholpen door het artikel te verrijken met een tweede lid (ter vervanging van art. 4.4 van het Omgevingsbesluit):

'2. De voorkeursbeslissing vermeldt welke oplossing de voorkeur van het bevoegd gezag heeft, hoe burgers, bedrijven, maatschappelijke organisaties en bestuursorganen zijn betrokken en wat de resultaten zijn van de uitgevoerde verkenning.'

Bovendien lijkt me dat met de keuze voor art. 5.49, onder a, niet volstaan kan worden met de aankondiging dat een project wordt uitgevoerd. De bedoeling is toch dat vooral aangegeven wordt wat de hoofdlijnen van het project worden (zie als voorbeeld art. 5 , tweede lid, van de Tracéwet). Mijn voorkeur zou het echter hebben als ook in art. 5.49 een derde lid zou worden opgenomen, waarin een globale beschrijving van het voorgenomen project wordt opgenomen:

'3. Indien de voorkeur, bedoeld in het eerste lid, uitgaat naar die, genoemd in onderdeel a, gekozen, bevat de voorkeursbeslissing een globale beschrijving van het project.'

Het is ronduit verwarrend door én te spreken van een kan-bepaling én vervolgens het woordje 'of' toe te voegen, waarmee de limitatieve opsomming wordt gegeven. Uit de wet volgt dat in de voorkeursbeslissing geen voorkeur hoeft te staan ('kan'), uit de AMvB volgt dat wel. Het uitsmeren van relevante bepalingen over twee lagen regelgeving is ook hier niet nodig.

24. Art. 4.4, eerste en tweede lid, Ob.

25. Zie ook art. 5.51 over de inhoud van het projectbesluit. 


\section{Het overgangsrecht}

Twee artikelen uit hoofdstuk 11 van de Invoeringswet Omgevingswet zijn op de studiemiddag aan de orde geweest:

1. Art. 11.4, waaruit blijkt dat als het ontwerp van een met afdeling 3.4 Awb voorbereid projectbesluit ter inzage is gelegd voor inwerkingtreding van de Omgevingswet, het oude recht van toepassing blijft:

'Als voor de inwerkingtreding van de Omgevingswet voor een ambtshalve te nemen besluit een ontwerp ter inzage is gelegd van een besluit op de voorbereiding waarvan afdeling 3.4 van de Algemene wet bestuursrecht van toepassing is, blijft het oude recht van toepassing:

a. als tegen het besluit beroep openstaat: tot het besluit onherroepelijk wordt,

b. als tegen het besluit geen beroep openstaat: tot het besluit van kracht wordt.'

2. Art. 11.61, derde lid, dat geschreven is om te voorkomen dat als de projectprocedure op grond van de Wtw zich in een vergevorderd stadium bevindt, de $(\mathrm{Ow}-)$ voornemenprocedure alsnog moet worden doorlopen:

'3. Als de procedure op grond van paragraaf 5.2 van de Waterwet ter voorbereiding van een projectplan als bedoeld in artikel 5.4 van die wet voor de inwerkingtreding van afdeling 5.2 van de Omgevingswet zich in een vergevorderd stadium bevindt, geen ontwerp van dat projectplan ter inzage is gelegd en is voldaan aan de bij of krachtens artikel 5.47, gestelde vereisten, en artikel 5.48, eerste lid, van de Omgevingswet, kan een ontwerp van een projectbesluit als bedoeld in artikel 5.44, eerste en derde lid, van de Omgevingswet worden vastgesteld.'

Een viertal opmerkingen bij art. 11.61, derde lid:

a. Waterschappen die al vergevorderd zijn met hun verkenning hoeven niet - als dat nog niet heeft geleid tot een ontwerp-projectplan - van voren af aan te beginnen met een verkenning. Een beloning voor proactief $\mathrm{Ow}$-gedrag dus. Verwezen wordt naar art. III, tweede lid, van de wet van 1 december 2011 tot wijziging van de Tracéwet met het oog op de versnelling en verbetering van besluitvorming over infrastructurele projecten. Maar daarin wordt niet gesproken van een 'vergevorderd' stadium. Weliswaar stond die term wel in het oorspronkelijk voorstel van wet, maar die is bij nota van wijziging gewijzigd in 'gevorderd' stadium, juist om discussie te voorkomen over de vraag of een project zich nu wel of niet in een vergevorderd stadium bevindt. Bovendien wordt in dat overgangsrecht verwezen naar een lijst waarop de projecten met naam genoemd werden waarvoor nog geen startbeslissing was genomen, maar de verkenning toch al een aanvang had genomen. De mogelijkheid tot het vast- stellen van een dergelijke lijst ontbreekt in het overgangsrecht en heeft tot gevolg dat bij eventuele geschillen over het niet toepassen van paragraaf 5.2.2 de vraag naar de vergevorderdheid van de verkenning centraal zal staan.

b. Wat ook opvalt an de toelichting is dat bij die vergevorderdheid gezegd wordt dat werkzaamheden die al verricht zijn in het kader van een milieueffectrapportage ook niet opnieuw behoeven te worden gedaan, mits de informatie in het rapport nog actueel genoeg is voor het te nemen projectbesluit. Dat is vreemd, want in de verkenningsfase is het meronderzoek nog niet aan de orde.

c. Er worden voorwaarden gesteld aan het overgangsrecht. Immers, voldaan moet zijn aan 'de bij of krachtens artikel 5.47, gestelde vereisten, en artikel 5.48, eerste lid, van de Omgevingswet'. Dat is vreemd, want je kunt niet vóór inwerkingtreding van de Omgevingswet voldoen aan die wettelijke vereisten. Ik zou menen dat deze voorwaarden beter geschrapt kunnen worden.

d. Het zal duidelijk zijn dat als de projectprocedure op grond van de Wtw nog niet heeft geleid tot het ter inzage leggen van een ontwerp-projectplan, dat er dan een ontwerp-projectbesluit ter inzage zal worden gelegd. In dat verband is het vreemd dat dan in het derde lid gezegd wordt dat een ontwerp van een projectbesluit als bedoeld in art. 5.44, eerste en derde lid, van de Omgevingswet 'kan' worden vastgesteld. Is er dan een andere keuze?

Er is naar mijn mening een verbetering mogelijk door zonder voorwaarden te bepalen dat als eenmaal kennisgegeven is van de start van de verkenning, de verkenningsfase kan worden overgeslagen. Of door net als in het overgangsrecht bij die wijziging van de Tracéwet de minister de bevoegdheid te geven om binnen een jaar na inwerkingtreding van de Omgevingswet een lijst op te stellen van projecten die zich in een gevorderd stadium bevinden en waarvoor paragraaf 5.2.2 van de Omgevingswet niet van toepassing is.

In hoeverre er behoefte is aan overgangsrecht dat ervoor zorgt dat als het ontwerp-projectplan nog niet vastgesteld is bij inwerkingtreding van de Omgevingswet het oude recht van toepassing blijft, weet ik niet. Immers zie daartoe de bijdragen van Frank Groothuijse en Hans Besselink -, de inhoud en het rechtskarakter van het projectbesluit zijn anders dan die van het projectplan. En dat maakt het lastig om te beslissen of al vóór inwerkingtreding van de Omgevingswet daarop moet worden voorgesorteerd. Nu vermoed ik wel dat voor de inwerkingtreding van de Omgevingswet het koninklijk besluit een ruime termijn zal geven. Een dergelijke termijn is nodig om een inschatting te kunnen maken of nog vóór inwerkingtreding een ontwerp-projectplan (Wtw) ter inzage kan worden gelegd. Als dat spannend wordt, is het beter om te wachten met het uitbrengen van een (dan) ontwerp-projectbesluit (Omgevingswet) en de tijd te gebruiken om de inhoud reeds af te stemmen op het 
omgevingsplan en na te denken of het projectbesluit ook andere vergunningen zal incorporeren.

\section{Conclusies}

Art. 5.47 en 5.48 van de Omgevingswet zijn stevig onderhanden genomen door de Tweede Kamer en dat heeft gezorgd voor een zwaar gejuridificeerde participatieregeling. Daar waar de regering op zich met een summiere algemene regeling volstond, zijn er door de Tweede Kamer, niet alleen gespeend van kennis van wetgeving, maar ook van toepassing van participatie in de praktijk, allerlei toeters en bellen toegevoegd, die geresulteerd hebben in een moeilijk uitvoerbare regeling, die de schone participatiebedoelingen om zeep gaat helpen.

Te vroeg in het participatieproces worden oplossingen gevraagd en beoordeeld. Door de veralgemenisering van de participatieartikelen blijven er weinigzeggende bepalingen over. Artikelen die door de amendering angevuld zijn met niet-nuttige of niet-noodzakelijke toevoegingen zorgen voor een ongewenste juridificering van de participatieprocedure. In paragraaf 3 is een citaat opgenomen waarin het kabinet aangeeft niet de vorm en de te volgen $\mathrm{T}_{\mathrm{w}}$-procedure vast te willen leggen om juridificering te voorkomen. Bij de Tracéwet heeft dat niet geleid tot amendering, bij de Omgevingswet echter wel.

Een en ander brengt de vraag terug of we niet beter af zijn met het geheel schrappen van paragraaf 5.2.2 van de Omgevingswet. Juist omdat in de praktijk niet alleen Rijkswaterstaat, maar ook de waterschappen ook zonder wettelijke regeling de omgeving om tal van goede redenen toch al in een vroegtijdig stadium plegen te betrekken en te raadplegen. Het onderschrijven en toepassen van de Code Maatschappelijke Participatie maakt een wettelijke regeling naar mijn mening geheel overbodig.

De kans is klein dat mijn aanbeveling om paragraaf 5.2.2 te schrappen wordt overgenomen. Mocht dat toch gebeuren, dan kan ook het overgangsrecht voor lopende participatieprojecten achterwege blijven. Als mijn aanbeveling niet wordt overgenomen, is het wel verstandig om art. 11.61, derde lid, van de Invoeringswet Omgevingswet te wijzigen. 